\title{
Coupled best approximation theorems for discontinuous operators in partially ordered Banach spaces
}

\author{
Dezhou Konga,b, Lishan Liü,c,*, Yonghong Wu \\ ${ }^{a}$ College of Information Science and Engineering, Shandong Agricultural University, Taian, 271018, Shandong, China. \\ ${ }^{b}$ School of Mathematical Sciences, Qufu Normal University, Qufu, 273165, Shandong, China. \\ ${ }^{c}$ Department of Mathematics and Statistics, Curtin University of Technology, Perth, WA 6845, Australia.
}

Communicated by Y. H. Yao

\begin{abstract}
In this paper, we first discuss properties of the cone in normed product spaces. As applications, we then derive some coupled best approximation and coupled coincidence best approximation point results for discontinuous operators in partially ordered Banach spaces. Some of our results generalize those obtained in earlier work. (c)2017 All rights reserved.
\end{abstract}

Keywords: Coupled fixed point, best approximation, metric projection, discontinuous operator, mixed monotone, Banach space.

2010 MSC: 41A65, 47H07, 06B30.

\section{Introduction}

A remarkable application of fixed-point theorems is to prove the existence of best approximation point in best approximation theory [8, 10, 11, 15, 18, 19, 21], which was introduced by Fan in [3] for normed linear spaces. Various aspects of best approximation theorem have been studied by many authors under different assumptions and many interesting results are obtained in the last decades $[7,9,14,16,17$, 23-25]. As generalization of fixed-points, coupled fixed points of a map $f$ satisfying some contractive or nonexpansive type condition have been studied by many authors and applied to various problems, especially to those associated with best approximation. In partially ordered metric spaces, the existence result of a coupled fixed point for contractions was proved in Bhaskar and Lakshmikantham [4]. This result was extended by Lakshmikantham and Ćirić [12]. In the paper, they also introduced a coupled coincidence point term. In [22], Mitrović obtained the existence results of a coupled best approximation point and derived some coupled coincidence and coupled fixed point results using the KKM technique. In [2], Amini-Harandi derived some best and coupled best approximations and coupled coincidence point results in normed spaces and hyperconvex metric spaces. However, some contractive or continuous conditions are required in the above mentioned work. In this paper, we first introduce the terminologies,

\footnotetext{
*Corresponding author

Email addresses: dezhoukong@163.com (Dezhou Kong), mathlls@163.com (Lishan Liu), Y.Wu@curtin.edu.au (Yonghong Wu) doi:10.22436/jnsa.010.06.09
} 
definitions and notations in partially ordered normed spaces. We prove some fundamental properties of the cone in normed product spaces. As applications, we then derive some coupled best approximation and coupled coincidence best approximation point results in partially ordered Banach spaces. Our results are noteworthy in the sense that no contractive and continuous assumptions is required and they are obtained by using the increasing characterizations of the metric projection.

\section{Preliminaries}

Let $X$ be a real topological vector space with the dual space $X^{*}$ and $K$ a nonempty closed convex subset of $X$. By $\theta$ we denote the zero element of $X$. The closed convex subset $K \subset X$ is called a cone if and only if it satisfies:

(i) $\lambda \mathrm{K} \subset \mathrm{K}$ for all $\lambda \geqslant 0$;

(ii) $\mathrm{K} \cap(-\mathrm{K})=\theta$;

(iii) $\mathrm{K}$ is $\operatorname{not}\{\theta\}$.

Given a cone $K \subset X$, we define a partial order $\preceq$ with respect to $K$ by $x \preceq y$ if and only if $y-x \in K$.

Let $(X, \preceq)$ be a partially ordered Banach space induced by $K$, if every two-element set $\{x, y\}$ has a least upper bound $\sup \{x, y\}$, we say that the cone $K$ is minihedral. For convenience, we denote $\sup \{x, y\}=x \vee y$, $\inf \{x, y\}=x \wedge y, x^{+}=x \vee \theta, x^{-}=(-x) \vee \theta$ and $|x|=x \vee(-x)$. The cone $K$ is called normal if there is a number $N>0$, such that for all $x, y \in X, 0 \preceq x \preceq y$ implies $\|x\| \leqslant N\|y\|$. The cone $K$ is called regular if every increasing sequence which is bounded from above is convergent. That is, if $\left\{x_{n}\right\}$ is a sequence such that $x_{1} \preceq x_{2} \preceq \cdots \preceq y$ for some $y \in X$, then there is $x \in X$ such that $\lim _{n \rightarrow \infty}\left\|x_{n}-x\right\|=0$. A set $C \subset X$ is bounded from above with respect to a cone $K$ if there is a $y \in X$ such that $x \preceq y$ for all $x \in C$, the element $y$ is called an upper bound for $C$. And if sup $C$ exists for every nonempty and bounded from above $C \subset X$, we say the cone $K$ is a strongly minihedral cone. For any $1 \leqslant p<\infty$, the norm $\|\cdot\|$ of $X$ is called $p$-additive if

$$
\|x+y\|^{p}=\|x\|^{p}+\|y\|^{p}, \quad \forall x, y \in X \text { with }|x| \wedge|y|=\theta .
$$

We refer the reader $[6,13]$ for the needed terminology and notation on the partial order.

Let $(X, \preceq)$ be a real partially ordered Banach space. Given $u_{0}, v_{0} \in X$ such that $u_{0} \prec v_{0}$, the set $\left[\mathfrak{u}_{0}, v_{0}\right]=\left\{z \in X: u_{0} \preceq z \preceq v_{0}\right\}$ is called an ordered interval. $F: X \rightarrow X$ is called increasing if

$$
x \preceq y \text { implies } F(x) \preceq F(y) .
$$

Let $(X, \preceq)$ be a real partially ordered Banach space with the dual space $X^{*}$ and $K$ a cone in $X$. Recall that

$$
\mathrm{K}^{*}=\left\{z^{*} \in \mathrm{X}^{*}:\left\langle z^{*}, x\right\rangle \geqslant 0, \quad \forall x \in \mathrm{K}\right\}
$$

is called the dual cone of $\mathrm{K}$.

We denote by $J$ the normalized duality mapping from $X$ to $2^{X^{*}}$ defined by

$$
\mathrm{Jx}=\left\{x^{*} \in \mathrm{X}^{*}:\left\langle x^{*}, x\right\rangle=\left\|x^{*}\right\|\|x\|,\|x\|=\left\|x^{*}\right\|\right\}, \quad x \in X .
$$

Many properties of the normalized duality mapping J have been studied. For the details, one may see [1].

$K$ is called orthogonal if $\langle J(x), y\rangle=0$ for any $x, y \in X$ with $|x| \wedge|y|=\theta$. The cone $K$ is called subdual if $\mathrm{J}(\mathrm{K}) \subseteq \mathrm{K}^{*}$ and superdual if $\mathrm{J}^{*}\left(\mathrm{~K}^{*}\right) \subseteq \mathrm{K}$.

Let $X$ be a real Banach space and $C$ a non-empty, closed and convex subset of $X$. The set-valued mapping $\mathrm{P}_{\mathrm{C}}: \mathrm{X} \rightarrow 2^{\mathrm{C}}$,

$$
P_{C}(x)=\left\{z \in C:\|x-z\|=\inf _{y \in C}\|x-y\|\right\}, \quad x \in X,
$$

is called the metric projection operator from $X$ onto $C$.

In [26], the metric projection operator satisfies the following variational characterization: 
Lemma 2.1 ([26]). Let $\mathrm{X}$ be a reflexive, strictly convex and smooth Banach space and $\mathrm{C}$ a closed and convex subset of $X$,

$$
x^{*}=\mathrm{P}_{\mathrm{C}}(\mathrm{x}) \Leftrightarrow\left\langle\mathrm{J}\left(\mathrm{x}-\mathrm{x}^{*}\right), \mathrm{y}-\mathrm{x}^{*}\right\rangle \leqslant 0, \quad \forall \mathrm{y} \in \mathrm{C} .
$$

This inequality is called the basic variational principle for $P_{C}$ in $X$.

Definition 2.2. Let $X$ be a partially ordered space and $D$ a subset of $X$. Then the map $f: D \times D \rightarrow X$ is said to be mixed monotone, if $f(x, y)$ is increasing in $x$ and is decreasing in $y$, that is, for any $x, y \in D$,

$$
x_{1}, x_{2} \in D, \quad x_{1} \preceq x_{2} \Rightarrow f\left(x_{1}, y\right) \preceq f\left(x_{2}, y\right),
$$

and

$$
y_{1}, y_{2} \in D, \quad y_{1} \succeq y_{2} \Rightarrow f\left(x, y_{1}\right) \preceq f\left(x, y_{2}\right) .
$$

Definition 2.3. Let $(X, \preceq)$ be a normed space and $D$ a subset of $X$. Let $f: D \times D \rightarrow X$ and $g: D \rightarrow X$.

(i) An element $\left(x^{*}, y^{*}\right) \in D \times D$ is called a coupled fixed point of $f$ if

$$
x^{*}=f\left(x^{*}, y^{*}\right), \quad y^{*}=f\left(y^{*}, x^{*}\right) .
$$

(ii) An element $\left(x^{*}, y^{*}\right) \in D \times D$ is called a coupled coincidence point of $f$ and $g$ if

$$
g\left(x^{*}\right)=f\left(x^{*}, y^{*}\right), \quad g\left(y^{*}\right)=f\left(y^{*}, x^{*}\right) .
$$

(iii) An element $\left(x^{*}, y^{*}\right) \in D \times D$ is called a coupled best approximation point of $f$ if

$$
\left\|x^{*}-f\left(x^{*}, y^{*}\right)\right\|+\left\|y^{*}-f\left(y^{*}, x^{*}\right)\right\|=\inf _{(x, y) \in D \times D}\left\{\left\|x-f\left(x^{*}, y^{*}\right)\right\|+\left\|y-f\left(y^{*}, x^{*}\right)\right\|\right\} .
$$

(iv) For a $p>1$, an element $\left(x^{*}, y^{*}\right) \in D \times D$ is called a $p$-coupled best approximation point of $f$ if

$$
\left\|x^{*}-f\left(x^{*}, y^{*}\right)\right\|^{p}+\left\|y^{*}-f\left(y^{*}, x^{*}\right)\right\|^{p}=\inf _{(x, y) \in D \times D}\left\{\left\|x-f\left(x^{*}, y^{*}\right)\right\|^{p}+\left\|y-f\left(y^{*}, x^{*}\right)\right\|^{p}\right\} .
$$

(v) An element $\left(x^{*}, y^{*}\right) \in D \times D$ is called a coupled coincidence best approximation point of $f$ if

$$
\left\|g\left(x^{*}\right)-f\left(x^{*}, y^{*}\right)\right\|+\left\|g\left(y^{*}\right)-f\left(y^{*}, x^{*}\right)\right\|=\inf _{(x, y) \in D \times D}\left\{\left\|g(x)-f\left(x^{*}, y^{*}\right)\right\|+\left\|g(y)-f\left(y^{*}, x^{*}\right)\right\|\right\} .
$$

(vi) For a $p>1$, an element $\left(x^{*}, y^{*}\right) \in D \times D$ is called a $p$-coupled coincidence best approximation point of $f$ if

$$
\begin{aligned}
\left\|g\left(x^{*}\right)-f\left(x^{*}, y^{*}\right)\right\|^{p} & +\left\|g\left(y^{*}\right)-f\left(y^{*}, x^{*}\right)\right\|^{p} \\
& =\inf _{(x, y) \in D \times D}\left\{\left\|g(x)-f\left(x^{*}, y^{*}\right)\right\|^{p}+\left\|g(y)-f\left(y^{*}, x^{*}\right)\right\|^{p}\right\} .
\end{aligned}
$$

In the following context, let $(X, \preceq)$ be a partially ordered Banach space with respect to a cone $K$ of $X$ and $X^{*}$ the dual space of $X$. Denote by $\|\cdot\|$ and $\|\cdot\|_{*}$ the norms of $X$ and $X^{*}$ and take

$$
\tilde{\mathrm{K}}=\{(x, y) \in X \times X: x \succeq \theta, y \preceq \theta\} .
$$

Obviously, $\tilde{\mathrm{K}}$ is a cone in $\mathrm{X} \times \mathrm{X}$. Then we induce the following partial order by $\tilde{\mathrm{K}}$ :

$$
\left(x_{1}, y_{1}\right) \preceq_{\tilde{K}}\left(x_{2}, y_{2}\right) \text {, if and noly if } x_{1} \preceq x_{2}, y_{1} \succeq y_{2} \text {. }
$$

We define the norm of $X \times X$ as:

$$
\|(x, y)\|=\left(\|x\|^{p}+\|y\|^{p}\right)^{\frac{1}{p}}, \forall(x, y) \in X \times X .
$$

Naturally, the norm of $X^{*} \times X^{*}$ is

$$
\|(x, y)\|_{*}=\left(\|x\|_{*}^{\mathrm{q}}+\|y\|_{*}^{\mathrm{q}}\right)^{\frac{1}{q}}, \quad \forall(x, y) \in X^{*} \times X^{*},
$$

where $p>0, q>0$ such that $\frac{1}{p}+\frac{1}{q}=1$. It is known that if $X$ is a reflexive, strictly convex and smooth Banach space, then $X \times X$ with the above norm is also a reflexive, strictly convex and smooth Banach space. 
Proposition 2.4. Let $\mathrm{X}$ be a reflexive, strictly convex and smooth Banach space and $\mathrm{K}$ a minihedral cone in $\mathrm{X}$. Suppose that $\mathrm{K}$ is orthogonal. Then $\tilde{\mathrm{K}}$ is a orthogonal cone in $\mathrm{X} \times \mathrm{X}$.

Proof. Now we prove that, for any $\theta \neq(x, y) \in X \times X$, we have

$$
J(x, y)=\left(\frac{\|x\|^{p-2} J x}{\|(x, y)\|^{p-2}}, \frac{\|y\|^{p-2} J y}{\|(x, y)\|^{p-2}}\right) .
$$

Indeed, since $\frac{1}{p}+\frac{1}{q}=1$, we have

$$
\begin{aligned}
\left\|\left(\frac{\|x\|^{p-2} J x}{\|(x, y)\|^{p-2}}, \frac{\|y\|^{p-2} J y}{\|(x, y)\|^{p-2}}\right)\right\|_{*}^{2} & =\left(\left\|\frac{\|x\|^{p-2} J x}{\|(x, y)\|^{p-2}}\right\|_{*}^{q}+\left\|\frac{\|y\|^{p-2} J y}{\|(x, y)\|^{p-2}}\right\|_{*}^{q}\right)^{\frac{2}{q}} \\
& =\left(\frac{\|x\|^{(p-2) q}}{\|(x, y)\|^{(p-2) q}}\|J x\|_{*}^{q}+\frac{\|y\|^{(p-2) q}}{\|(x, y)\|^{(p-2) q}\|J y\|_{*}^{q}}\right)^{\frac{2}{q}} \\
& =\left(\frac{\|x\|^{p q-q}}{\|(x, y)\|^{(p-2) q}}+\frac{\|y\|^{p q-q}}{\|(x, y)\|^{(p-2) q}}\right)^{\frac{2}{q}} \\
& =\left(\frac{\|x\|^{p}+\|y\|^{p}}{\|(x, y)\|^{(p-2) q}}\right)^{\frac{2}{q}}=\left(\frac{\|(x, y)\|^{p}}{\|(x, y)\|^{(p-q)}}\right)^{\frac{2}{q}} \\
& =\|(x, y)\|^{2} .
\end{aligned}
$$

Also since

$$
\begin{aligned}
\left\langle\left(\frac{\|x\|^{p-2} J x}{\|(x, y)\|^{p-2}}, \frac{\|y\|^{p-2} J y}{\|(x, y)\|^{p-2}}\right),(x, y)\right\rangle & =\frac{\|x\|^{p-2}\langle J x, x\rangle}{\|(x, y)\|^{p-2}}+\frac{\|y\|^{p-2}\langle J y, y\rangle}{\|(x, y)\|^{p-2}} \\
& =\frac{\|x\|^{p}+\|y\|^{p}}{\|(x, y)\|^{p-2}}=\frac{\|(x, y)\|^{p}}{\|(x, y)\|^{p-2}} \\
& =\|(x, y)\|^{2}
\end{aligned}
$$

we get that (2.1) holds. Take $\left(x_{1}, y_{1}\right),\left(x_{2}, y_{2}\right) \in X \times X$ such that $\left|\left(x_{1}, y_{1}\right)\right| \wedge\left|\left(x_{2}, y_{2}\right)\right|=(\theta, \theta)$. By the definition of $\tilde{K}$, we obtain that $\left|x_{1}\right| \wedge\left|x_{2}\right|=\theta,\left(-\left|y_{1}\right|\right) \vee\left(-\left|y_{2}\right|\right)=\theta$, that is, $\left|x_{1}\right| \wedge\left|x_{2}\right|=\theta,\left|y_{1}\right| \wedge\left|y_{2}\right|=\theta$. If $\left(x_{1}, y_{1}\right)=(\theta, \theta)$, it is easy to see that $\left\langle J\left(x_{1}, y_{1}\right),\left(x_{2}, y_{2}\right)\right\rangle=0$. If $\left(x_{1}, y_{1}\right) \neq(\theta, \theta)$, as $K$ is orthogonal, we have $\left\langle J x_{1}, x_{2}\right\rangle=0$ and $\left\langle J y_{1}, y_{2}\right\rangle=0$, which implies that

$$
\left\langle J\left(x_{1}, y_{1}\right),\left(x_{2}, y_{2}\right)\right\rangle=\frac{\left\|x_{1}\right\|^{p-2}\left\langle J x_{1}, x_{2}\right\rangle}{\left\|\left(x_{1}, y_{1}\right)\right\|^{p-2}}+\frac{\left\|y_{1}\right\|^{p-2}\left\langle J y_{1}, y_{2}\right\rangle}{\left\|\left(x_{1}, y_{1}\right)\right\|^{p-2}}=0 .
$$

Thus $\tilde{\mathrm{K}}$ is orthogonal. The assertion is proved.

Proposition 2.5. Let $\mathrm{X}$ be a reflexive, strictly convex and smooth Banach space and $\mathrm{K}$ a cone in $\mathrm{X}$. Suppose that $\mathrm{K}$ is subdual. Then $\tilde{\mathrm{K}}$ is a subdual cone in $\mathrm{X} \times \mathrm{X}$.

Proof. If $\left(x_{1}, y_{1}\right)=(\theta, \theta)$, it is obvious that $J\left(x_{1}, y_{1}\right) \in \tilde{K}^{*}$. From Proposition 2.4, we get that, for any $\theta \neq\left(x_{1}, y_{1}\right) \in \tilde{\mathrm{K}}$,

$$
J\left(x_{1}, y_{1}\right)=\left(\frac{\left\|x_{1}\right\|^{p-2} J x_{1}}{\left\|\left(x_{1}, y_{1}\right)\right\|^{p-2}}, \frac{\left\|y_{1}\right\|^{p-2} J y_{1}}{\left\|\left(x_{1}, y_{1}\right)\right\|^{p-2}}\right)
$$

Thus, for any $(x, y) \in \tilde{K}$,

$$
\left\langle J\left(x_{1}, y_{1}\right),(x, y)\right\rangle=\frac{\left\|x_{1}\right\|^{p-2}\left\langle J x_{1}, x\right\rangle}{\left\|\left(x_{1}, y_{1}\right)\right\|^{p-2}}+\frac{\left\|y_{1}\right\|^{p-2}\left\langle J y_{1}, y\right\rangle}{\left\|\left(x_{1}, y_{1}\right)\right\|^{p-2}}
$$


Since $K$ is subdual, we have $\left\langle J x_{1}, x\right\rangle \geqslant 0$ and

$$
\left\langle J y_{1}, y\right\rangle=\left\langle J\left(-y_{1}\right),-y\right\rangle \geqslant 0
$$

Hence

$$
\left\langle J\left(x_{1}, y_{1}\right),(x, y)\right\rangle \geqslant 0 .
$$

It follows that $\mathrm{J}\left(\mathrm{x}_{1}, \mathrm{y}_{1}\right) \in \tilde{\mathrm{K}}^{*}$. Then $\tilde{\mathrm{K}}$ is a subdual cone.

Proposition 2.6. Let $\mathrm{X}$ be a normed space and $\mathrm{K}$ a minihedral cone in $\mathrm{X}$. Suppose that the norm $\|\cdot\|$ of $\mathrm{X}$ is $\mathrm{p}^{\prime}$-additive and the norm to $\mathrm{X} \times \mathrm{X}$ is defined by

$$
\|(x, y)\|=\left(\|x\|^{p^{\prime}}+\|y\|^{p^{\prime}}\right)^{\frac{1}{p^{\prime}}}, \forall(x, y) \in X \times X,
$$

where $\mathrm{p}^{\prime}>1$. Then the norm of $\mathrm{X} \times \mathrm{X}$ is $\mathrm{p}^{\prime}$-additive.

Proof. Take any $\left(x_{1}, y_{1}\right),\left(x_{2}, y_{2}\right) \in X \times X$ such that $\left|\left(x_{1}, y_{1}\right)\right| \wedge\left|\left(x_{2}, y_{2}\right)\right|=(\theta, \theta)$. Then

$$
(\theta, \theta)=\left(\left|x_{1}\right|,-\left|y_{1}\right|\right) \wedge\left(\left|x_{2}\right|,-\left|y_{2}\right|\right)=\left(\left|x_{1}\right| \wedge\left|x_{2}\right|,\left(-\left|y_{1}\right|\right) \vee\left(-\left|y_{2}\right|\right)\right)
$$

which implies that

$$
\left|x_{1}\right| \wedge\left|x_{2}\right|=\theta, \quad\left|y_{1}\right| \wedge\left|y_{2}\right|=-\left(-\left|y_{1}\right|\right) \vee\left(-\left|y_{2}\right|\right)=\theta .
$$

Since the norm $\|\cdot\|$ of $X$ is $p^{\prime}$-additive, we obtain that

$$
\begin{aligned}
\left\|\left(x_{1}, y_{1}\right)+\left(x_{2}, y_{2}\right)\right\|^{p^{\prime}} & =\left\|\left(x_{1}+x_{2}, y_{1}+y_{2}\right)\right\|^{p^{\prime}} \\
& =\left\|x_{1}+x_{2}\right\|^{p^{\prime}}+\left\|y_{1}+y_{2}\right\|^{p^{\prime}} \\
& =\left\|x_{1}\right\|^{p^{\prime}}+\left\|x_{2}\right\|^{p^{\prime}}+\left\|y_{1}\right\|^{p^{\prime}}+\left\|y_{2}\right\|^{p^{\prime}} \\
& =\left\|\left(x_{1}, y_{1}\right)\right\|^{p^{\prime}}+\left\|\left(x_{2}, y_{2}\right)\right\|^{p^{\prime}} .
\end{aligned}
$$

The assertion is proved.

\section{Coupled best approximation theorem}

We obtain some characterizations of the cone in product spaces in the above section. Now we prove the following coupled best approximation theorems by the above properties.

Theorem 3.1. Let $\mathrm{X}$ be a reflexive, strictly convex and smooth Banach space and $\mathrm{K}$ a minihedral, orthogonal and subdual cone. Suppose that the following conditions are satisfied:

(i) $\mathrm{f}: \mathrm{K} \times \mathrm{K} \rightarrow \mathrm{X}$ is mixed monotone;

(ii) $\mathrm{f}$ is bounded from above;

(iii) there exists an $\left(x_{0}, y_{0}\right) \in K \times K$ such that $y_{0} \preceq f^{+}\left(y_{0}, x_{0}\right), f^{+}\left(x_{0}, y_{0}\right) \preceq x_{0}$, where $f^{+}(x, y)=f(x, y) \vee \theta$.

Then $\mathrm{f}$ has the minimum $\mathrm{p}$-coupled best approximation point.

Proof. Define $\mathrm{h}: \mathrm{K} \times \mathrm{K} \rightarrow \mathrm{X} \times \mathrm{X}$ and $\mathrm{F}: \mathrm{K} \times \mathrm{K} \rightarrow \mathrm{K} \times \mathrm{K}$ as

$$
h(x, y)=(f(x, y), f(y, x)), \quad \forall(x, y) \in K \times K,
$$

and

$$
F(x, y)=P_{K \times K}(h(x, y)), \quad \forall(x, y) \in K \times K \text {. }
$$


Take any $(x, y) \in X \times X,\left(z_{1}, z_{2}\right) \in K \times K$, by orthogonality of $K$, we have

$$
\begin{aligned}
\left\langle J\left((x, y)-\left(x^{+}, y^{+}\right)\right),\left(x^{+}, y^{+}\right)-\left(z_{1}, z_{2}\right)\right\rangle & =\left\langle-J\left(\left(x^{-}, y^{-}\right)\right),\left(x^{+}, y^{+}\right)-\left(z_{1}, z_{2}\right)\right\rangle \\
& =-\left\langle J\left(\left(x^{-}, y^{-}\right)\right),\left(x^{+}, y^{+}\right)\right\rangle+\left\langle J\left(\left(x^{-}, y^{-}\right)\right),\left(z_{1}, z_{2}\right)\right\rangle \\
& =\left\langle J\left(x^{-}, y^{-}\right),\left(z_{1}, z_{2}\right)\right\rangle .
\end{aligned}
$$

Following the same argument as the proof of Proposition 2.5, we can obtain that

$$
\left\langle\mathrm{J}\left(\mathrm{x}^{-}, \mathrm{y}^{-}\right),\left(z_{1}, z_{2}\right)\right\rangle \geqslant 0 \text {. }
$$

From Lemma 2.1, we have

$$
P_{K \times K}(x, y)=\left(x^{+}, y^{+}\right), \quad \forall(x, y) \in X \times X
$$

Thus

$$
F(x, y)=\left(f^{+}(x, y), f^{+}(y, x)\right), \quad \forall(x, y) \in K \times K .
$$

Let $D=\left\{(x, y) \in K \times K:(x, y) \succeq_{\tilde{K}} F(x, y)\right\}$. It is easy to see that $\left(x_{0}, y_{0}\right) \in D$, which implies that $D$ is nonempty. From Proposition 2.5, we have $\tilde{\mathrm{K}}$ is subdual. It follows that $\tilde{\mathrm{K}}$ is normal. As $\mathrm{X}$ is reflexive, $\tilde{\mathrm{K}}$ is regular. By [5, Theorem 2.3.1], we have $\tilde{K}$ is strongly minihedral. Since $f$ is bounded from above, we have there exists a lower bound of $D$. Then there exists an $\left(x^{*}, y^{*}\right)=\inf D$. As $f$ is mixed monotone, $h$ is increasing, which implies that $F$ is increasing. Since $(x, y) \in D$ such that $(x, y) \succeq_{\tilde{K}}\left(x^{*}, y^{*}\right)$, we obtain that

$$
(x, y) \succeq_{\tilde{K}} F(x, y) \succeq_{\tilde{K}} F\left(x^{*}, y^{*}\right) .
$$

So $F\left(x^{*}, y^{*}\right)$ is a lower bound of D. It follows that

$$
\left(x^{*}, y^{*}\right) \succeq_{\tilde{K}} F\left(x^{*}, y^{*}\right) .
$$

Thus, $F\left(x^{*}, y^{*}\right) \succeq_{\tilde{K}} F\left(F\left(x^{*}, y^{*}\right)\right)$. Consequently, $F\left(x^{*}, y^{*}\right) \in D$. And hence,

$$
\mathrm{F}\left(x^{*}, \mathrm{y}^{*}\right) \succeq_{\tilde{\mathrm{K}}}\left(x^{*}, \mathrm{y}^{*}\right) .
$$

By (3.1) and (3.2), we have $F\left(x^{*}, y^{*}\right)=\left(x^{*}, y^{*}\right)$, that is,

$$
P_{K \times K}\left(f\left(x^{*}, y^{*}\right), f\left(y^{*}, x^{*}\right)\right)=\left(x^{*}, y^{*}\right) .
$$

Therefore,

$$
\left\|\left(x^{*}, y^{*}\right)-\left(f\left(x^{*}, y^{*}\right), f\left(y^{*}, x^{*}\right)\right)\right\|=\inf _{(x, y) \in K \times K}\left\|(x, y)-\left(f\left(x^{*}, y^{*}\right), f\left(y^{*}, x^{*}\right)\right)\right\| .
$$

By the definition of the norm on $X \times X$, we obtain that

$$
\begin{aligned}
\left\|x^{*}-f\left(x^{*}, y^{*}\right)\right\|^{p} & +\left\|y^{*}-f\left(y^{*}, x^{*}\right)\right\|^{p} \\
& =\inf _{(x, y) \in K \times K}\left\{\left\|x-f\left(x^{*}, y^{*}\right)\right\|^{p}+\left\|y-f\left(y^{*}, x^{*}\right)\right\|^{p}\right\} .
\end{aligned}
$$

If $(x, y)$ is another $p$-coupled best approximation point, we have $(x, y) \in D$. It follows that $(x, y) \succeq\left(x^{*}, y^{*}\right)$. Then $\left(x^{*}, y^{*}\right)$ is the minimum $p$-coupled best approximation point. The assertion is proved.

Example 3.2. Let $(X, \preceq)=\left(\ell_{\mathfrak{p}}^{n}, \preceq\right)$, where $1<p<\infty$ and $\preceq$ is induced by the cone

$$
K=\left\{\left(x_{1}, x_{2}, \cdots, x_{n}\right): x_{1} \geqslant 0, x_{2} \geqslant 0, \cdots, x_{n} \geqslant 0\right\} .
$$

Obviously, $\tilde{K}=K \times(-K)$ is a minihedral, orthogonal and subdual cone in $X \times X$. Take $x_{0}, y_{0} \in K$, such that $\mathrm{y}_{0} \preceq \frac{1}{2} \mathrm{x}_{0}$. Define $\mathrm{f}: \mathrm{K} \times \mathrm{K} \rightarrow \mathrm{X}$ as

$$
f(x, y)= \begin{cases}\left(x-\frac{1}{2} x_{0}\right) \vee\left(-y+2 y_{0}\right), & (x, y) \succeq_{\tilde{K}}\left(x_{0}, y_{0}\right), \\ -\frac{1}{2} x_{0}, & (x, y) \succeq_{\tilde{K}}\left(x_{0}, y_{0}\right) .\end{cases}
$$


It is easy to prove that $f$ is mixed monotone. Since

$$
f^{+}\left(y_{0}, x_{0}\right)=\frac{1}{2} x_{0} \succeq y_{0}, \quad f^{+}\left(x_{0}, y_{0}\right)=\frac{1}{2} x_{0} \vee 2 y_{0} \preceq x_{0} .
$$

Take $\left(x_{0}^{\prime}, y_{0}^{\prime}\right)=\left(\frac{1}{6} x_{0}, 8 x_{0}\right) \in K \times K$, it is easy to see that if $(x, y) \preceq_{\tilde{K}}\left(x_{0}^{\prime}, y_{0}^{\prime}\right), f^{+}(x, y)=\frac{1}{2} x_{0} \succeq x, f^{+}(y, x)=$ $y-\frac{1}{2} x_{0} \preceq y$. Then all conditions of Theorem 3.1 are satisfied. Thus $f$ has the minimum $p$-coupled best approximation point in $\mathrm{K} \times \mathrm{K}$.

Theorem 3.3. Let $X$ be a reflexive, strictly convex and smooth Banach space and $\mathrm{K}$ a minihedral, orthogonal and subdual cone. Let $\mathfrak{u}_{0}, v_{0} \in \mathrm{X}$ and $\mathrm{u}_{0} \prec v_{0}$. Suppose that the following conditions are satisfied:

(i) $f:\left[u_{0}, v_{0}\right] \times\left[u_{0}, v_{0}\right] \rightarrow X$ is mixed monotone;

(ii) the norm $\|\cdot\|$ on $\mathrm{X}$ is $\mathrm{p}$-additive.

Then $\mathrm{f}$ has a p-coupled best approximation point $\left(\mathrm{x}^{*}, \mathrm{y}^{*}\right)$ in $\left[\mathrm{u}_{0}, v_{0}\right] \times\left[\mathrm{u}_{0}, v_{0}\right]$. Moreover,

$$
\begin{aligned}
& u_{0} \preceq u_{1} \preceq \cdots \preceq u_{n} \preceq \cdots \preceq x^{*} \preceq \cdots \preceq v_{n} \preceq \cdots \preceq v_{1} \preceq v_{0} \\
& u_{0} \preceq u_{1} \preceq \cdots \preceq u_{n} \preceq \cdots \preceq y^{*} \preceq \cdots \preceq v_{n} \preceq \cdots \preceq v_{1} \preceq v_{0}
\end{aligned}
$$

where

$$
\begin{aligned}
f_{1}(x, y) & =\left(f(x, y) \vee u_{0}\right) \wedge v_{0}, \quad f_{2}(x, y)=\left(f(y, x) \wedge v_{0}\right) \vee u_{0}, \\
u_{n} & =f_{1}\left(u_{n-1}, v_{n-1}\right), \quad v_{n}=f_{2}\left(u_{n-1}, v_{n-1}\right), \quad(n=1,2,3, \cdots) .
\end{aligned}
$$

Proof. Define $h:\left[u_{0}, v_{0}\right] \times\left[u_{0}, v_{0}\right] \rightarrow X \times X$ and $F:\left[u_{0}, v_{0}\right] \times\left[u_{0}, v_{0}\right] \rightarrow\left[u_{0}, v_{0}\right] \times\left[u_{0}, v_{0}\right]$ as

$$
h(x, y)=(f(x, y), f(y, x)), \quad \forall(x, y) \in\left[u_{0}, v_{0}\right] \times\left[u_{0}, v_{0}\right],
$$

and

$$
F(x, y)=P_{\left[u_{0}, v_{0}\right] \times\left[u_{0}, v_{0}\right]}(h(x, y)), \quad \forall(x, y) \in\left[u_{0}, v_{0}\right] \times\left[u_{0}, v_{0}\right] .
$$

From Proposition 2.6, we know the norm of $X \times X$ is also p-additive. By [20, Lemma 2.5], we have

$$
F(x, y)=\left(h(x, y) \vee\left(u_{0}, v_{0}\right)\right) \wedge\left(v_{0}, u_{0}\right)=\left(\left(f(x, y) \vee u_{0}\right) \wedge v_{0},\left(f(y, x) \wedge v_{0}\right) \vee u_{0}\right)
$$

Since $f$ is mixed monotone, we have $F$ is increasing. From Proposition 2.5, we know $\tilde{K}$ is subdual, which implies $\tilde{K}$ is normal. Since $X$ is reflexive, we have $\tilde{K}$ is regular. From [5, Theorem 3.1.4], we obtain that there exists $\left(x^{*}, y^{*}\right)$ in $\left[u_{0}, v_{0}\right] \times\left[u_{0}, v_{0}\right]$ such that

$$
F\left(x^{*}, y^{*}\right)=\left(x^{*}, y^{*}\right)
$$

moreover

$$
\begin{aligned}
\left(\mathrm{u}_{0}, v_{0}\right) \preceq \mathrm{F}\left(\mathrm{u}_{0}, v_{0}\right) & \preceq \cdots \preceq \mathrm{F}^{\mathrm{n}}\left(\mathrm{u}_{0}, v_{0}\right) \preceq \cdots \preceq\left(x^{*}, \mathrm{y}^{*}\right) \\
& \preceq \cdots \preceq \mathrm{F}^{\mathrm{n}}\left(v_{0}, \mathrm{u}_{0}\right) \preceq \cdots \preceq \mathrm{F}\left(v_{0}, \mathrm{u}_{0}\right) \preceq\left(v_{0}, \mathrm{u}_{0}\right) .
\end{aligned}
$$

Then (3.3) and (3.4) hold.

Remark 3.4. If $X$ is a reflexive, strictly convex and smooth Banach lattice and $f$ is continuous, $\mathrm{P}_{\left[\mathfrak{u}_{0}, v_{0}\right] \times\left[\mathfrak{u}_{0}, v_{0}\right]}$ in Theorem 3.3 is continuous, then $u_{n} \rightarrow x^{*}, v_{n} \rightarrow y^{*}(n \rightarrow \infty)$.

\section{Coupled coincidence best approximation theorem}

In this section, based on the results on coupled coincidence points, which were introduced by Lakshmikantham and Ćirić [12], we obtain the following coupled coincidence best approximation theorem.

Definition 4.1 ([12]). Let $(X, \preceq)$ be a partially ordered space and $D$ a nonempty subset of $X$. Let $f$ : $D \times D \rightarrow X$ and $g: D \rightarrow X$. Then $f$ is said to be $g$-mixed monotone if $f(x, y)$ is $g$-increasing in $x$ and is 
$g$-decreasing in $y$, that is, for any $x, y \in D$,

$$
x_{1}, x_{2} \in D, \quad g\left(x_{1}\right) \preceq g\left(x_{2}\right) \Rightarrow f\left(x_{1}, y\right) \preceq f\left(x_{2}, y\right),
$$

and

$$
y_{1}, y_{2} \in D, \quad g\left(y_{1}\right) \succeq g\left(y_{2}\right) \Rightarrow f\left(x, y_{1}\right) \preceq f\left(x, y_{2}\right) .
$$

Definition 4.2 ([12]). Let $X$ be a vector space and $D$ a nonempty subset of $X$. Let $f: D \times D \rightarrow D$ and $g: D \rightarrow D$. Then $f$ and $g$ are said to be commutable if

$$
g(f(x, y))=f(g(x), g(y)), \quad \forall x, y \in D
$$

Theorem 4.3. Let $\mathrm{X}$ be a reflexive, strictly convex and smooth Banach space and $\mathrm{K}$ a minihedral, orthogonal and subdual cone. Suppose that $\mathrm{f}: \mathrm{K} \times \mathrm{K} \rightarrow \mathrm{X}$ and $\mathrm{g}: \mathrm{K} \rightarrow \mathrm{X}$ satisfy the following conditions:

(i) $\mathrm{f}$ is g-mixed monotone and $\mathrm{f}^{+}(\mathrm{K} \times \mathrm{K}) \subset \mathrm{g}(\mathrm{K})$;

(ii) $\mathrm{f}^{+}$and $\mathrm{g}$ are continuous and commutable;

(iii) there exists a $v \in \mathrm{K}$ such that $\mathrm{f}^{+}(\mathrm{K} \times \mathrm{K}) \preceq v$;

(iv) there exists an $\left(x_{0}, y_{0}\right) \in K \times K$ such that $g\left(x_{0}\right) \preceq f^{+}\left(x_{0}, y_{0}\right), f^{+}\left(y_{0}, x_{0}\right) \preceq g\left(y_{0}\right)$.

Then $\mathrm{f}$ has at least one $\mathrm{p}$-coupled coincidence best approximation point $\left(\mathrm{x}^{*}, \mathrm{y}^{*}\right)$ in $\mathrm{K} \times \mathrm{K}$. Moreover, if

$$
g\left(x_{n}\right)=f^{+}\left(x_{n-1}, y_{n-1}\right), g\left(y_{n}\right)=f^{+}\left(y_{n-1}, x_{n-1}\right), \quad(n=1,2,3, \cdots),
$$

then

$$
g\left(x_{n}\right) \rightarrow x^{*}, g\left(y_{n}\right) \rightarrow y^{*}(n \rightarrow \infty) .
$$

Proof. We define $\mathrm{h}: \mathrm{K} \times \mathrm{K} \rightarrow \mathrm{X} \times \mathrm{X}$ and $\mathrm{F}: \mathrm{K} \times \mathrm{K} \rightarrow \mathrm{K} \times \mathrm{K}$ as

$$
h(x, y)=(f(x, y), f(y, x)), \quad \forall(x, y) \in K \times K,
$$

and

$$
F(x, y)=P_{K \times K}(h(x, y)), \quad \forall(x, y) \in K \times K .
$$

Since $f$ is $g$-mixed monotone, we obtain that $h$ is $g$-increasing in $x$ and $y$. From Proposition 2.4 and Proposition 2.5, we obtain that $\tilde{K}$ is a minihedral, orthogonal and subdual cone, which implies that $P_{K \times K}(x, y)=\left(x^{+}, y^{+}\right)$is increasing. Thus

$$
F(x, y)=\left(f^{+}(x, y), f^{+}(y, x)\right), \quad \forall(x, y) \in K \times K,
$$

is $g$-increasing in $x$ and $y$. By $f^{+}\left(y_{0}, x_{0}\right) \preceq g\left(y_{0}\right), f^{+}\left(x_{0}, y_{0}\right) \succeq g\left(x_{0}\right)$, we have

$$
\left(g\left(x_{0}\right), g\left(y_{0}\right)\right) \preceq \tilde{K} F\left(x_{0}, y_{0}\right) .
$$

Since $f^{+}(K \times K) \subset g(K)$, there exists an $\left(x_{1}, y_{1}\right) \in K \times K$ such that $\left(g\left(x_{1}\right), g\left(y_{1}\right)\right)=F\left(x_{0}, y_{0}\right)$. Using $f^{+}(K \times K) \subset g(K)$, there exists an $\left(x_{2}, y_{2}\right) \in K \times K$ such that $\left(g\left(x_{2}\right), g\left(y_{2}\right)\right)=F\left(x_{1}, y_{1}\right)$. By induction, there exists a sequence $\left\{\left(x_{n}, y_{n}\right)\right\} \subset K \times K$ such that

$$
\left(g\left(x_{n+1}\right), g\left(y_{n+1}\right)\right)=F\left(x_{n}, y_{n}\right) .
$$

Now we prove that $\left\{\left(g\left(x_{n}\right), g\left(y_{n}\right)\right)\right\}$ is increasing. When $n=0$,

$$
\left(g\left(x_{0}\right), g\left(y_{0}\right)\right) \preceq_{\tilde{K}} F\left(x_{0}, y_{0}\right)=\left(g\left(x_{1}\right), g\left(y_{1}\right)\right) .
$$


Thus, for $\mathrm{n}=0$,

$$
\left(g\left(x_{0}\right), g\left(y_{0}\right)\right) \preceq_{\tilde{K}}\left(g\left(x_{1}\right), g\left(y_{1}\right)\right) .
$$

Assume that for $n=k,\left(g\left(x_{k}\right), g\left(y_{k}\right)\right) \preceq_{\tilde{K}}\left(g\left(x_{k+1}\right), g\left(y_{k+1}\right)\right)$ holds, that is,

$$
g\left(x_{k}\right) \preceq g\left(x_{k+1}\right), \quad g\left(y_{k}\right) \succeq g\left(y_{k+1}\right) .
$$

As $\mathrm{F}$ is g-mixed monotone, we have

$$
\left(g\left(x_{k+2}\right), g\left(y_{k+2}\right)\right)=F\left(x_{k+1}, y_{k+1}\right) \succeq_{\tilde{k}} F\left(x_{k}, y_{k}\right)=\left(g\left(x_{k+1}\right), g\left(y_{k+1}\right)\right) .
$$

Therefore, $\left\{\left(g\left(x_{n}\right), g\left(y_{n}\right)\right)\right\}$ is increasing, that is,

$$
\left(g\left(x_{1}\right), g\left(y_{1}\right)\right) \preceq_{\tilde{K}}\left(g\left(x_{2}\right), g\left(y_{2}\right)\right) \preceq_{\tilde{K}} \cdots \preceq_{\tilde{K}}\left(g\left(x_{n}\right), g\left(y_{n}\right)\right) \preceq_{\tilde{K}} \cdots .
$$

Since $f^{+}(K \times K) \preceq v,\left(g\left(x_{n+1}\right), g\left(y_{n+1}\right)\right)=\left(f^{+}\left(x_{n}, y_{n}\right), f^{+}\left(y_{n}, x_{n}\right)\right)$, we have

$$
\left(g\left(x_{1}\right), g\left(y_{1}\right)\right) \preceq_{\tilde{K}}\left(g\left(x_{2}\right), g\left(y_{2}\right)\right) \preceq_{\tilde{K}} \cdots \preceq_{\tilde{K}}\left(g\left(x_{n}\right), g\left(y_{n}\right)\right) \preceq_{\tilde{K}} \cdots \preceq_{\tilde{K}}(v, \theta) .
$$

Since $\tilde{K}$ is subdual, we have $\tilde{K}$ is normal. Also since $X$ is reflexive, it follows that $\tilde{K}$ is regular. Thus $\left(g\left(x_{n}\right), g\left(y_{n}\right)\right)$ is convergent. Let $\lim _{n \rightarrow \infty}\left(g\left(x_{n}\right), g\left(y_{n}\right)\right)=\left(x^{*}, y^{*}\right)$. As $g$ is continuous, we have

$$
\lim _{n \rightarrow \infty}\left(g\left(g\left(x_{n+1}\right)\right), g\left(g\left(y_{n+1}\right)\right)\right)=\left(g\left(x^{*}\right), g\left(y^{*}\right)\right) .
$$

Since $g$ and $f^{+}$are commutable, we obtain that

$$
\begin{aligned}
\left(g\left(g\left(x_{n+1}\right)\right), g\left(g\left(y_{n+1}\right)\right)\right) & =\left(g\left(f^{+}\left(x_{n}, y_{n}\right)\right), g\left(f^{+}\left(y_{n}, x_{n}\right)\right)\right) \\
& =\left(f^{+}\left(g\left(x_{n}\right), g\left(y_{n}\right)\right), f^{+}\left(g\left(y_{n}\right), g\left(x_{n}\right)\right)\right) .
\end{aligned}
$$

Applying continuity of $f^{+}$, we obtain that

$$
\begin{aligned}
\left(g\left(x^{*}\right), g\left(y^{*}\right)\right) & =\lim _{n \rightarrow \infty}\left(g\left(g\left(x_{n+1}\right)\right), g\left(g\left(y_{n+1}\right)\right)\right) \\
& =\lim _{n \rightarrow \infty}\left(g\left(f^{+}\left(x_{n}, y_{n}\right)\right), g\left(f^{+}\left(y_{n}, x_{n}\right)\right)\right) \\
& =\lim _{n \rightarrow \infty}\left(f^{+}\left(g\left(x_{n}\right), g\left(y_{n}\right)\right), f^{+}\left(g\left(y_{n}\right), g\left(x_{n}\right)\right)\right) \\
& =\left(f^{+}\left(\lim _{n \rightarrow \infty} g\left(x_{n}\right), \lim _{n \rightarrow \infty} g\left(y_{n}\right)\right), f^{+}\left(\lim _{n \rightarrow \infty} g\left(y_{n}\right), \lim _{n \rightarrow \infty} g\left(x_{n}\right)\right)\right) \\
& =\left(f^{+}\left(x^{*}, y^{*}\right), f^{+}\left(y^{*}, x^{*}\right)\right) .
\end{aligned}
$$

Thus

$$
\left(g\left(x^{*}\right), g\left(y^{*}\right)\right)=P_{K \times K}\left(f\left(x^{*}, y^{*}\right), f\left(y^{*}, x^{*}\right)\right) .
$$

Then

$$
\begin{aligned}
\|\left(g\left(x^{*}\right), g\left(y^{*}\right)\right)- & \left(f\left(x^{*}, y^{*}\right), f\left(y^{*}, x^{*}\right)\right) \| \\
& =\inf _{(x, y) \in K \times K}\left\|(x, y)-\left(f\left(x^{*}, y^{*}\right), f\left(y^{*}, x^{*}\right)\right)\right\| .
\end{aligned}
$$

By the definition of the norm on $X \times X$, we have

$$
\begin{aligned}
\left\|g\left(x^{*}\right)-f\left(x^{*}, y^{*}\right)\right\|^{p} & +\left\|g\left(y^{*}\right)-f\left(y^{*}, x^{*}\right)\right\|^{p} \\
& =\inf _{(x, y) \in K \times K}\left\{\left\|x-f\left(x^{*}, y^{*}\right)\right\|^{p}+\left\|y-f\left(y^{*}, x^{*}\right)\right\|^{p}\right\} .
\end{aligned}
$$

The assertion is proved.

Remark 4.4. When $\mathrm{g}$ is the identity mapping, Theorem 4.3 becomes the coupled best approximation theorem. 
Example 4.5. Let $(X, \preceq)=\left(\ell_{\mathfrak{p}}^{n}, \preceq\right)$, where $1<p<\infty$. The cone is the same as that in Example 3.2. Take $v \in \mathrm{K}$. We define $\mathrm{f}: \mathrm{K} \times \mathrm{K} \rightarrow \mathrm{X}$ as

$$
f(x, y)= \begin{cases}x-y, & (x, y) \preceq_{\tilde{K}}(v, v), \\ \theta, & (x, y) \swarrow_{\tilde{K}}(v, v) .\end{cases}
$$

For any $x \in K, g(x)=2 x$. It is easy to see that $f$ is $g$-mixed monotone. We have $f(K \times K)$ is bounded from above and $g\left(f^{+}(x, y)\right)=\theta=f^{+}(g(x), g(y))$. Take $\left(x_{0}, y_{0}\right)=(\theta, \theta)$, it is easy to prove that $\left(x_{0}, y_{0}\right)$ satisfies the condition (iv). Thus all conditions in Theorem 4.3 are satisfied. Then $f$ has at least one p-coupled coincidence best approximation point in $\mathrm{K} \times \mathrm{K}$.

\section{Acknowledgment}

The authors were supported financially by the NationaNatural Science Foundation of China (11371221, 11571296), the Natural Science Foundation of Shandong Province (ZR2014AM034) and the China Postdoctoral Science Foundation (2017M612307).

\section{References}

[1] Y. Alber, Metric and generalized projection operators in Banach spaces: properties and applications, Theory and applications of nonlinear operators of accretive and monotone type, Lecture Notes in Pure and Appl. Math., Dekker, New York, 178 (1996), 15-50. 2

[2] A. Amini-Harandi, Best and coupled best approximation theorems in abstract convex metric spaces, Nonlinear Anal., 74 (2011), 922-926. 1

[3] K. Fan, Extensions of two fixed point theorems of F. E. Browder, Math. Z., 112 (1969), 234-240. 1

[4] T. Gnana Bhaskar, V. Lakshmikantham, Fixed point theorems in partially ordered metric spaces and applications, Nonlinear Anal., 65 (2006), 1379-1393. 1

[5] D.-J. Guo, Y. J. Cho, J. Zhu, Partial ordering methods in nonlinear problems, Nova Science Publishers, Inc., Hauppauge, NY, (2004). 3, 3

[6] D.-J. Guo, V. Lakshmikantham, Nonlinear problems in abstract cones, Notes and Reports in Mathematics in Science and Engineering, Academic Press, Inc., Boston, MA, (1988). 2

[7] M. Jleli, B. Samet, Remarks on the paper: Best proximity point theorems: an exploration of a common solution to approximation and optimization problems, Appl. Math. Comput., 228 (2014), 366-370. 1

[8] D.-Z. Kong, L.-S. Liu, Y.-H. Wu, Best approximation and fixed-point theorems for discontinuous increasing maps in Banach lattices, Fixed Point Theory Appl., 2014 (2014), 10 pages. 1

[9] D.-Z. Kong, L.-S. Liu, Y.-H. Wu, The best approximation theorems and fixed point theorems for discontinuous increasing mappings in Banach spaces, Abstr. Appl. Anal., 2015 (2015), 7 pages. 1

[10] D.-Z. Kong, L.-S. Liu, Y.-H. Wu, Isotonicity of the metric projection with applications to variational inequalities and fixed point theory in Banach spaces, J. Fixed Point Theory Appl., 2016 (2016), 15 pages. 1

[11] D.-Z. Kong, L.-S. Liu, Y.-H. Wu, Isotonicity of the metric projection by Lorentz cone and variational inequalities, J. Optim. Theory Appl., 173 (2017), 117-130. 1

[12] V. Lakshmikantham, L. Ćirić, Coupled fixed point theorems for nonlinear contractions in partially ordered metric spaces, Nonlinear Anal., 70 (2009), 4341-4349. 1, 4, 4.1, 4.2

[13] J.-L. Li, E. A. Ok, Optimal solutions to variational inequalities on Banach lattices, J. Math. Anal. Appl., 388 (2012), 1157-1165. 2

[14] T.-C. Lin, S.-H. Park, Approximation and fixed-point theorems for condensing composites of multifunctions, J. Math. Anal. Appl., 233 (1998), 1-8. 1

[15] L.-S. Liu, On approximation theorems and fixed point theorems for non-self-mappings in infinite-dimensional Banach spaces, J. Math. Anal. Appl., 188 (1994), 541-551. 1

[16] L.-S. Liu, Random approximations and random fixed point theorems in infinite-dimensional Banach spaces, Indian J. Pure Appl. Math., 28 (1997), 139-150. 1

[17] L.-S. Liu, Some random approximations and random fixed point theorems for 1-set-contractive random operators, Proc. Amer. Math. Soc., 125 (1997), 515-521. 1

[18] L.-S. Liu, Random approximations and random fixed point theorems for random 1-set-contractive non-self-maps in abstract cones, Stochastic Anal. Appl., 18 (2000), 125-144. 1

[19] L.-S. Liu, Approximation theorems and fixed point theorems for various classes of 1-set-contractive mappings in Banach spaces, Acta Math. Sin. (Engl. Ser.), 17 (2001), 103-112. 1 
[20] L.-S. Liu, D.-Z. Kong, Y.-H. Wu, The best approximation theorems and variational inequalities for discontinuous mappings in Banach spaces, Sci. China Math., 58 (2015), 2581-2592. 3

[21] J. Markin, N. Shahzad, Best approximation theorems for nonexpansive and condensing mappings in hyperconvex spaces, Nonlinear Anal., 70 (2009), 2435-2441. 1

[22] Z. D. Mitrović, A coupled best approximations theorem in normed spaces, Nonlinear Anal., 72 (2010), 4049-4052. 1

[23] S. Sadiq Basha, Best proximity point theorems: an exploration of a common solution to approximation and optimization problems, Appl. Math. Comput., 218 (2012), 9773-9780. 1

[24] S. Sadiq Basha, N. Shahzad, Common best proximity point theorems: global minimization of some real-valued multiobjective functions, J. Fixed Point Theory Appl., 18 (2016), 587-600.

[25] N. Shahzad, Fixed point and approximation results for multimaps in S-KKM class, Nonlinear Anal., 56 (2004), 905-918. 1

[26] C. Zălinescu, Convex analysis in general vector spaces, World Scientific Publishing Co., Inc., River Edge, NJ, (2002). $2,2.1$ 